\title{
CONDITIONALS AND DISJUNCTIONS IN MENTAL-LOGIC THEORY: A RESPONSE TO LIU AND CHOU (2012) AND TO LÓPEZ ASTORGA (2013)
}

\author{
Condicionales y disyunciones en la teoría de la lógica mental: Una respuesta a Liu y \\ Chou (2012) y a López Astorga (2013)
}

David P. O’Brien*

\begin{abstract}
Liu and Chou (2012) presented a two-step theory to describe reasoning both on the four traditional conditional syllogisms and on four parallel syllogisms that replace the conditional with a disjunction. This article proposes that although Liu and Chou show that the words if and or play an important role in generating the data they report, their theory provides no explanation of how these words play any role. The article also corrects an assertion by López Astorga (2013) that mental-logic theory accounts for the findings of Liu and Chou by interpreting if as the material conditional. Instead I show why mental-logic theory rejects the material conditional and accounts for the data using a proceduralsemantics approach to the meaning of logic particles. The article concludes that a theory like that of Liu and Chou requires something like mental-logic theory to account for their data.
\end{abstract}

Keywords: Mental logic, reasoning, modus ponens, modus tollens, conditional reasoning, deductive reasoning, disjunctions, probabilistic reasoning.

\section{RESUMEN}

Liu y Chou (2012) plantearon una teoría de dos pasos para describir el razonamiento tanto con respecto a los silogismos condicionales tradicionales como en lo relativo a cuatro silogismos paralelos que reemplazan el condicional por una disyunción. Este artículo propone que, si bien Liu y Chou muestran que los términos si y o desempeñan un papel importante en la generación de los datos que presentan, su teoría no proporciona una explicación acerca de cómo esos términos desempeñan tal papel. El artículo también corrige una afirmación de López Astorga (2013) referente a que la teoría de la lógica mental explica los hallazgos de Liu y Chou en base a la interpretación de si como un condicional material. Yo muestro, por el contrario, por qué la teoría de la lógica mental rechaza el

\footnotetext{
* Baruch College and the City University of New York. New York, Estados Unidos.

E-mail address: david.obrien@baruch.cuny.edu

Received June, 11, 2014. Accepted June, 13, 2014.
} 
condicional material y explico los datos recurriendo a un enfoque procedimental semántico para las partículas lógicas. El artículo concluye que una teoría como la de Liu y Chou necesita algo similar a la teoría de la lógica mental para interpretar sus resultados.

Palabras clave: Lógica mental, razonamiento, modus ponens, modus tollens, razonamiento condicional, razonamiento deductivo, disyunciones, razonamiento probabilístico.

Contemporary debates concerning logical reasoning tend to reflect their ancient origins, generally without noticing. Logic as a formal Western discipline began with the proposals of Aristotle, as well as the Megarians, in particular Philo of Megara, and the Stoics, in particular Chrysippus. Aristotle came to dominate much of Western philosophical thinking for the better part of two millennia, so the works of the Megarian and Stoic logicians went largely forgotten -indeed, some of their ideas were misattributed to Aristotle- but with the advent of the propositional calculus in the early 20th century their ideas have taken on a renewed interest (See Barnes, Bobzien, \& Mignucci, 1999; Bobzien, 2002; Kapp, 1942; and Kneale and Kneale, 1962, for detailed presentations of the Hellenic origins of Western logic). The present article addresses research reported by Liu and Chou (2012), which has been critiqued by López Astorga (2013) in this journal. Some of the basic assumptions of this debate stem from proposals about logic made two millennia ago, and I will discuss how understanding those origins and their strengths and weaknesses can help us interpret the recent debate. The standard propositional calculus of the sort found in most recent introductory logic textbooks presents sentential operators like $\supset, \equiv, \vee, \neg$, and $\wedge$, which are referred to as the operators for conditionals, bi-conditionals, disjunctions, negations, and conjunctions, respectively. With the addition of quantifiers like the universal, $\forall$, and the existential, $\exists$, the propositional calculus becomes a first-order predicate calculus. In English, the propositional operators are typically rendered with words like if, if-and-only-if, or, not, and and, and the universal and existential quantifiers with all and some, although identifying a particular natural- language word with the operators or quantifiers can be misleading, for example, both if and suppose can be used to convey conditionals, and both and and but can convey conjunctions. Nonetheless, a theory of logical reasoning needs to connect the logic processes to the usual ways that propositions are conveyed in natural languages. Contemporary logic textbooks tend to define the operators in terms of a logical semantics in the form of truth tables, and to provide some inference procedures with which to draw sound conclusions from premise sets, that is, conclusions that inherit the truth of the propositions on which they are based. These two notions of a truth-functional logical semantics and a separate set of inference procedures have their origins with the ancient logicians Philo of Megara and Chyrsippus, respectively.

Whereas Aristotelian logic was based on analyses of terms, the Megarians began focusing logic on propositions, that is, statements that take on truth values, using truth functional assignments. Philo of Megara is best remembered for providing a logical semantics for conditionals that became known as the material conditional: 


\begin{tabular}{cccc}
$\mathrm{p}$ & $\mathrm{q}$ & $\mathrm{p}$ & $\supset \mathrm{q}$ \\
\hline $\mathrm{t}$ & $\mathrm{t}$ & $\mathrm{t}$ & \\
$\mathrm{f}$ & $\mathrm{t}$ & $\mathrm{t}$ & \\
$\mathrm{t}$ & $\mathrm{f}$ & $\mathrm{f}$ & \\
$\mathrm{f}$ & $\mathrm{f}$ & $\mathrm{t}$
\end{tabular}

On this interpretation of conditionals, $p \supset q$ is true so long as $p$ is false or $q$ is true, making $p \supset q$ equivalent in this truth-functional sense to not- $p$ or $q$. This truth table definition for the material conditional was criticized by contemporaries of Philo of Megara because of its paradoxical nature, particularly the notion that the falsity of the antecedent is sufficient to ensure the truth of a conditional-the proposition If 4 is a prime number then the Queen of Scotland authored this article is true from the perspective of the material conditional simply because its antecedent clause is false. One might at this point think the problem is with Philo of Megara's choice of truth table, and perhaps an alternative truth table could be found to account for if without leading to such paradoxes. Such a hope, however, seems unfounded, because in more than two millenia no other truth table has been able to supplant the material conditional as a truth-functional account of the semantics of if. Let me suggest that the problem is not in the choice of which truth table should represent if, but in the choice of using a truth table to represent if. The alternative is not to use a truth table to describe the logical semantics of if, but to use a set of inference procedures in which if is not $\supset$.

The Stoic logicians followed the Megarians in thinking of logic as propositional, with the most relevant of the Stoics for the way we think about conditionals being Chrysippus, who began to think of propositional logic in terms of inference forms or inference procedures. Chrysippus identified the modus-ponens (if $p$ then $q, p, \therefore q$ ) and modus-tollens (if $p$ then $q$, not- $q, \therefore$ not-p) argument forms that were addressed by Liu and Chou (2012), as well as three other argument forms: modus ponendo tollens (1) (not both $p$ and $q, p, \therefore$, not $q$ ), modus ponendo tollens (2) ( $p$ or $q, p, \therefore$, not $q$ ), and modus tollendo ponens ( $p$ or $q$, not- $p, \therefore, q)^{1}$. Modus ponendo tollens (1) holds that when the negation of a conjunction is a major premise and one of its components is true, then the other component can be asserted as false. Modus ponendo tollens (2) applies to an exclusive disjunction and holds that when one of its components is true, the other can be asserted as false. Modus tollendo ponens applies both to inclusive and to exclusive disjunctions and holds that when an or-proposition is a major premise and one of its component propositions is false, the other can be asserted as true.

One can think of these Chrysippian argument forms in two quite different ways. In the first interpretation, they simply are descriptions of argument forms that happen to be sound. In the second, they may be taken as proof procedures that can be used to assert conclusions when premises of the requisite forms are encountered, for example, the modus-ponens procedure holds that when one knows both if $p$ then $q$ and $p$, one can assert

\footnotetext{
${ }^{1}$ Chrysippus was Greek, but his inference forms took on these Latin names over the centuries.
} 
$q$ for all $p s$ and all $q s$. Note that although modus ponens and modus tollens are consistent with the truth table assignments of the material conditional, they are not, and should not be taken to be, the same as the material conditional. One can construct a system of propositional logic in which modus ponens and modus tollens hold, but in which if is not the material conditional, as I shall discuss later.

Modus ponens and modus tollens usually are included among the inference forms presented in modern logic textbooks, although modus tollendo ponens and the two modus ponendo tollens forms tend not to be. How any particular inference form survives or not in a logic system can be capricious, somewhat in the manner of the QWERTY keyboard surviving long after being constructed to solve a particular mechanical problem in early manual typewriters. There is no guarantee that the choice, even in a logic system, is itself logical. In the work leading to the mental-logic theory that I constructed with the late Martin Braine (e.g., Braine \& O’Brien, 1998), which was intended as a theory of the basic architecture of human deductive reasoning, the answer concerning which inference forms to include and which to exclude was in large part empirical, that is, addressable in terms of which inferences are made largely without error, occur early in development, and are universal, that is, available across languages, cultures, and levels of education and literacy (see Chapter 4 of Braine \& O'Brien, 1998). These are not the same concerns that have been followed by the authors of standard logic textbooks, whose professional interest in largely in the construction of metalogical proofs of consistency and completeness. I take it that such metalogical issues are not what should concern a researcher interested in discovery of what is natural in human reasoning. I shall return to this later.

Chrysippus did not tie the inference forms he described to any truth tables, and he did not seem to to be concerned about whether they in any way reflected truth-functional assignments. Instead, he thought the inferences were self evident. He noted in the third century B.C.E. that even a dog following a scent on a road who comes to a fork in the road understands that when the scent does not go down one branch of the fork, it must go down the other. The ability of even preschool children to understand this logic inference can be seen in the game in which an adult hides a coin in one hand. When it is revealed not to be in the left hand, a child understands it must be in the right hand. This example of the modus-tollendo-ponens inference shows that these inference forms were considered sufficiently self-evident to the Stoic logicians that they needed no foundation in truth tables, but stood on their own. The Stoics thus provided an approach to propositional logic in which inferences rather than truth-table assignments are fundamental, and the inference forms are not based on truth-functional assignments.

If the human mind were to represent propositions of the form if $p$ then $q$ as the material conditional, however, then one would expect that replacing if $p$ then $q$ with not- $p$ or $q$ in a reasoning problem would not change the reasoning process (because the process would be based on the same truth table), except for the following caveat: Disjunctions have been associated with two different truth tables in standard logic, one for an inclusive disjunction and one for an exclusive disjunction. This leads to the two following truth tables for not-p or $q$, the first for an inclusive disjunction and the second for an exclusive disjunction: 


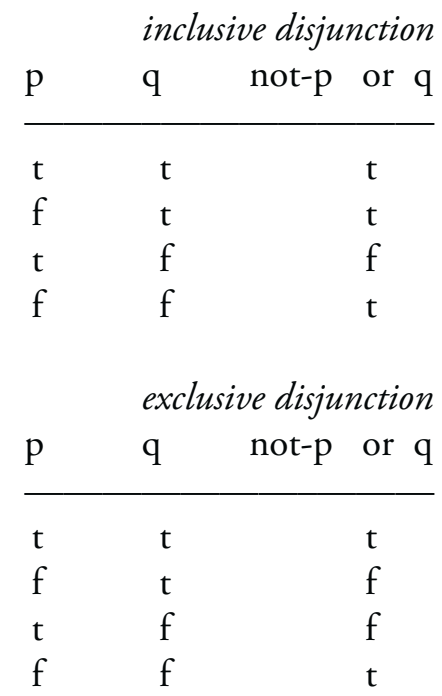

A mind interpreting or inclusively and if as the material conditional thus would be expected to represent if $p$ then $q$ and not-p or $q$ with the same truth tables. A mind interpreting or exclusively, however, would represent not-p or $q$ with the same truth table as the material bi-conditional, $p$ if and only if $q$, rather than as the material conditional. Liu and Chou (2012) investigated whether conditionals and disjunctions are represented psychologically in terms of the material-conditional truth table and thus whether the two words, if and or, have the same meaning as one another. To be clear from the beginning, Liu and Chou predicted that the two kinds of propositions would not provide data consistent with one another. A word of caution about their enterprise is in order, however. The tasks they presented could not lead to responses consistent with the material truth table because, although the truth table contains bivalent assignments for falsity and truth, the tasks presented by Liu and Chou required probabilistic responses that ranged between 0 and 1 .

Liu and Chou (2012) proposed that laboratory participants' responses to the traditional conditional syllogisms -the valid modus-ponens and modus-tollens arguments, as well as the fallacious affirmation-of-the-consequent (if $p$ then $q, q, \therefore p$ ) and denialof-the-antecedent (if $p$ then $q$, not- $p, \therefore$ not- $q$ ) forms- follow from a two-step cognitive process, which they referred to as the first and second conditionalizations. Their approach can be illustrated with the modus- ponens syllogism. According to Liu and Chou, when presented the two premises if $p$ then $q$ and $p$, and with $q$ as a conclusion to be evaluated, a reasoner will first compute the probability of the conclusion, $q$, given the second premise, $p$, that is, $\mathrm{P}(\mathrm{q} \mid \mathrm{p})$, which they assume is influenced by the reasoner's knowledge about "real world events" (p. 677); they refer to this as the first conditionalization. For example, given that a person moves into a new house, how probable is it that that person will add some furniture? In making such an assessment a reasoner presumably will use his/her knowledge about how people behave when moving into a new house, so Liu and Chou call this knowledge-based reasoning. Note that at this first step in the two step process, the reasoner does not even consider the major premise, if $p$ then $q$, but only the minor premise, $p$, and the conclusion, $q$. It is only at the second step that the major premise is considered, 
as the reasoner then takes into account that the conditional premise is supposed to be considered as true, and then computes $P$ ( $p$ therefore $q \mid$ if $p$ then $q$ ), which they refer to as the second conditionalization.

Liu and Chou (2012) described several ways that this process might play out. Some participants might be able to follow the instructions to assume that the conditional premise is true, that is, that $\mathrm{P}=1.00$, which Liu and Chou said is "to detach from reality" (p. 677). These participants would then make the modus-ponens inference. Some would be "unable to detach from reality completely" (p. 677), and would assume that the conditional has less than a complete chance of being true, and others would attempt to follow instructions to assume the conditional is true although they still maintain some doubt about this. Such computations presumably influence the probability with the modus ponens inference is evaluated, as only when the conditional is assumed to have $\mathrm{P}=1.00$ would $p$ be sufficient for $q$. Further complicating matters, Liu and Chou wrote that the distinction between the computations of the two steps they propose "is only theoretical" (p. 677), and the two might be processed simultaneously-which, of course, is problematic for a researcher trying to understand how these computations are being proposed to occur in real time (unless one concludes that Liu's and Chou's proposal is metaphorical rather than an information-processing model).

Nonetheless, they assume that something akin to these two steps will lead to the likelihood of a modus-ponens inference being accepted, with the probability in any case ranging between $\mathrm{P}(\mathrm{q} \mid \mathrm{p})$ and 1.00 , and with acceptance of a modus-ponens inference relying on detecting $p$ as completely sufficient for $q$ "by detaching from reality" (p. 677). This description strikes me as odd in that it seems to require that in order to be logical one must detach from reality, that is, to be attached to reality blocks one from applying logic in reasoning. This truly is a view of logic that places it entirely in the academic and outside the practical, which leads one to ask why bio- evolutionary processes would have endowed us with such facilities.

In describing the materials for their empirical studies, Liu and Chou (2012) described some conditionals in which the perceived sufficiency of $p$ for $q$ is sufficiently high that real-world knowledge should not interfere in making a modus-ponens inference, e.g. if Person $H$ is not a man, then Person $H$ is a woman, if it is a dog, then it is an animal. Barring the possibility that a research participant might think of a transgender person or or a hermaphrodite, or of a stuffed toy dog or a mechanical dog or a metaphorical dog, such cases appear to be akin to tautologies in the manner of if a design has three sides, then it is a triangle -the sort of thing a Kantian would refer to as leading to analytic reasoning devoid of contingent empirical content. So, to reason according to the logic of conditionals, one either reasons about tautologies or one detaches from reality. At the other extreme, Liu and Chou presented some examples of low sufficiency conditionals- if someone is not wearing a suit, then that person is going to a bank, which seems not only to convey a low sufficiency of $\mathrm{p}$ for $\mathrm{q}$, but seems counterintuitive in terms of stereotypes; are people in swim suits found more often in banks than are people wearing suits? One almost expects Liu and Chou to include something eye-poppingly startling, such as if a woman is extremely ugly, then she is a high paid fashion model.

Two kinds of tasks were presented by Liu and Chou (2012): A reduced task version and a complete task version. The reduced version of the task was designed to correspond 
to the first step in their two step process, for example, asking for the probability of $q$ given $p$ without presenting a major premise of either a conditional or a disjunctive kind. A complete problem version was designed to correspond to the second step in their two step process, for example, asking for the probability of $p$ therefore $q$ given if not- $p$ then $q$ or given $p$ or $q$. Liu and Chou were interested in comparing what they saw as parallel syllogisms with if not $p$ then $q$ and with $p$ or $q$ as the major premises. So, the reduced task version for a problem with premises if not $p$ then $q$ and not- $p$ was identical to the reduced task version for a problem with premises $p$ or $q$ and not- $p$, although the complete task versions differed for the two problems in that one included if not- $p$ then $q$ and the other included $p$ or $q$. Any difference in responses to the complete tasks versions that have one or the other of the two sorts of major premises compared to the partial version that have no major premises thus must have to do with difference in the effects of the if and the or premises that are included only in the complete task versions. Further, a comparison between a reduced and a complete version allowed comparison of the contribution of the content of a problem with and without a logical operator in a major premise.

One would not expect any difference between conditional and disjunctive problems on the reduced task-after all the conditional and disjunction problems were identical since neither if nor or are mentioned in the reduced task, and Liu and Chou (2012) reported unsurprisingly that there were no significant differences. On the complete problems, that is, when the conditional or the disjunctive premise was mentioned, the data showed a difference between modus ponens and modus tollens for problems with a conditional premise, and that difference increased as one moved from problems with high sufficiency content to problems with low sufficiency content, but no such differences were found when the major premise was a disjunction.

Liu and Chou interpreted this finding as showing that even though both conditional and disjunctive problems share the same truth assignments of the material conditional, the meanings of if and or are different for the two, with if-statements more sensitive than or-statements to the levels of sufficiency in the content for modus ponens and modus tollens problems. Liu and Chou did not explain, however, what it is about if and or that makes if more sensitive to sufficiency than is or. Indeed, they said relatively little about how the meanings of if-statements and or-statements differ except to say that or normally conveys alternatives. The only way they discuss what it means for or to convey alternatives was in a discussion of why they used the $p$ or $q$ form to match with if not- $p$ then $q$, rather than using not-p or $q$ to match with if $p$ then $q$. In everyday language, they wrote, one disjunct in a disjunction should not include another, but not-p is likely to include $q$ "because $p$ is generally different from $q$ " (p. 684). Although I am not sure what this means, they provided an example, Either it is not a dog or it is an animal, which they wrote is much more difficult to comprehend than the comparable conditional, If it is a dog, then it is an animal. They concluded that it is thus not feasible to test the material interpretation hypothesis by contrasting if $p$ then $q$ with not-p or $q$. Given that they illustrated their point only with the an example, allow me to provide another example, Either Miguel is not drinking or he is drunk, which has the truth-functionally comparable conditional, if Miguel is drinking then he is drunk, both of which seem to be perfectly comprehensible. Not only is their point about this difference in meaning between conditionals and disjunctions 
difficult to follow, but they provided no theory at all concerning what the difference is between conditional sentences and disjunctive sentences, nor do they explain how that would account for the pattern of responses they report. In brief, they presented no theory of the meaning of if and no theory of the meaning of or, although they explained their data in terms of a presumed difference in meaning between if and $o r$.

Liu and Chou (2012) proposed that their two step process explains their data, but they have not been clear about how the two steps work in ordinary reasoning outside the scope of these two-premise syllogisms, and they even say at one point that the twosteps are merely theoretical in the sense that they might occur simultaneously rather than successively. My reading is that the two steps are better as a description of their research design than of how the human mind represents the content and form of if or or propositions.

López Astorga (2013) responded to Liu and Chou (2012), arguing in favor of two alternative explanations to account for the data they reported on modus-ponens and modus-tollens problems: (a) the mental-models approach (e.g., Johnson-Laird \& Byrne, 2002), and (b) an approach that claims human reasoning is governed by formal logical rules that treat conditionals as the material conditional. López Astorga identified several different theorists with this second approach, including Henle (1962), O'Brien (2009), Rips (1994), and Beth and Piaget (1966). The inclusion of O'Brien among these citations is problematic, however, given that O'Brien consistently has rejected the psychological plausibility of the material conditional as a representation of conditionals. I shall return to this point later.

Because of space limitations, I will not address how López Astorga presented the mental- models and formal-rule-theory accounts of Liu's and Chou's data, but will turn instead to the mental-logic theory that was presented in its most complete form in Braine and O'Brien (1998), and for if in particular in Braine and O'Brien (1991) to explain how it can deal with these data. The mental-logic theory consists of a set of logic schemas, a reasoning program that implements the schemas in the construction of lines of reasoning, and a set of pragmatic principles. The reasoning program includes both a direct-reasoning routine (the DRR) and a set of strategies that go beyond the DRR. The DRR is claimed to be universal, but the strategies are not, although they are commonly available to university students. I describe the schemas and reasoning program first for if and then for or.

Two principal schemas are provided for if, that is, for conditionals: modus ponens and a schema for conditional proof. First, the schema for conditional proof: To derive or evaluate if $p$ then ... first suppose $p$; for any proposition $q$ that follows from the supposition of $p$ taken together with other information assumed, one may assert if $p$ then $q$. Thus, when the consequent of a conditional can be derived from a set of premises taken together with the antecedent of the conditional as a hypothetical assumption, then the conditional can be asserted on the premises alone ${ }^{2}$. The DRR provides a routine that is used when a conditional conclusion is to be evaluated, for example, as the tentative conclusion of a logical argument; the antecedent of the conditional is added to the premise set as an

\footnotetext{
${ }^{2}$ Braine and O'Brien (1991) described a constraint on this schema that is not in standard logic systems: No proposition that is incompatible with the supposition can be introduced in a line of reasoning under the supposition. I will not discuss that constraint here.
} 
additional premise, and the consequent of the conditional is treated as a conclusion to be evaluated. Thus, when a premise set taken together with $p$ leads to $q$, if $p$ then $q$ is judged true, but when a premise set taken together with $p$ leads to not- $q$, if $p$ then $q$ is judged false. Note that this latter judgment would not follow in a standard logic that proposes the material conditional, $\supset$, as the logical semantics for if because $p$ might be false. Braine, Reiser, and Rumain (1984) found that college students' judgments are consistent with the mental-logic procedure rather than with standard logic, and O'Brien, Dias, Roazzi, and Braine (1998) replicated this finding with school-age children. The data thus support the claim of mental-logic theory that if is not $\supset$.

The schema for conditional proof illustrates why a modus ponens inference, that is, if $p$ then $q$ and $p$, therefore $q$, is sound. The basis for the assertion of a proposition of the form if $p$ then $q$ under the schema for conditional proof is that the supposition of $p$ entails $q$, so the replacement of the suppositional nature of $p$ with an assertion of the truth of $p$ entails the truth of $q$ on the premise set. These two schemas, modus ponens and the schema for conditional proof, provide the meaning of if, not with the logical semantics of the truth table for the material conditional, but with a procedural semantics (see discussions in O'Brien and Li, 2013, and Braine \& O'Brien, 1998, Chapter 4, of the procedural semantics of mental logic theory and the language of thought hypothesis) ${ }^{3}$.

Now I turn to the principal schema for disjunction, which is an extension of the argument form modus tollendo ponens of Chrysippus to which I referred earlier:

$$
\mathrm{p}_{1} \text { OR } \ldots \text { OR } \mathrm{p}_{\mathrm{n}} ; \sim \mathrm{p}_{\mathrm{i}} \therefore \mathrm{p}_{1} \text { OR } \ldots \text { OR } \mathrm{p}_{\mathrm{i}-1} \text { OR } \mathrm{p}_{\mathrm{i}+1} \text { OR } \ldots \text { OR } \mathrm{p}_{\mathrm{n}}
$$

which in the case of $p$ or $q$ and not- $p$ allows one to assert $q \cdot{ }^{4}$ Note that when one considers the schema for conditional proof together with this Chrysippian schema for disjunction, one can derive if not-p then $q$ from $p$ or $q$; one begins by supposing not-p, which feeds the inference of $q$ from $p$ or $q$, allowing the inference of if-not $p$ then $q$ from $p$ or $q$ alone. The fact that if not- $p$ then $q$ can be derived from $p$ or $q$ does not mean that the two expressions have the same meaning or that either one or both propositions are represented by a truth table, much less the truth table for the material conditional. Remember, both children and adults will infer that if $p$ then $q$ is false when the supposition of $p$ leads to a derivation of not-q, and this is not an inference that would follow if one were reasoning from a mental representation of the material conditional. The fact that if not-p then $q$ can be derived from $p$ or $q$ does not mean that either propositional form reflects the material conditional. Indeed, the derivation does not rely on the notion that propositions have truth tables or any other sort of truth-functional assignments.

I turn now to the relative reasoning difficulties of (a) if $p$ then $q$, not-q $\therefore$ not $p$ and (b) not-p or q, not-q, $\therefore$ not-p, that is, to the two problems that Liu and Chou wrote about as the conditional and disjunctive versions of modus tollens. In the procedures of mentallogic theory, the premises of not-p or $q$ and not- $q$ lead straightforwardly to not- $p$ through the application of the disjunction schema of Chrysippus that is part of the reasoning repertory

\footnotetext{
${ }^{3}$ Modus tollens is not included as a basic schema because empirical investigation shows that its inference is not accepted consistently. In the theory, modus-tollens inferences require a strategy that includes a negation- introduction schema.

${ }^{4}$ It also would allow one to assert $p$ from $p$ or $q$ and not- $q$, as the inference schema is not directional.
} 
of mental-logic theory. The reasoning required for if $p$ then $q$ and not- $q$ to not- $p$, however, is more complex. One begins by supposing $p$ to be true, which, through the modus-ponens schema leads to $q$; this inference of $q$ directly contradicts the minor premise, $n o t-q$, and by a reductio-ad-adsurdum schema (which also can be referred to as a negation-introduction schema) leads to the assertion of not-p. ${ }^{5}$ Clearly, the proof required for a response to the problem with a conditional major premise is more complex than than for the problem with a disjunctive major premise because it requires a reasoning strategy, whereas the disjunction-premise problem is solvable through the DRR. This does not mean, however, that all responses that accept not- $p$ as following from if $p$ then $q$ and not- $q$ result from a reductio argument; Braine and O'Brien (1998) argued that many such responses follow not from a reductio argument, but from a biconditional-like pragmatic interpretation of if. This interpretation of the data for modus tollens is supported by a developmental trend discussed in O'Brien, Dias, and Roazzi (1998) in which younger children make more correct answers on these problems that do older children, which Braine and O'Brien interpreted as following from the inappropriate application of pragmatic principles that lessens with increasing age.

From the perspective of mental-logic theory, the fact that not-p or $q$ and if $p$ then $q$ both can refer to the same truth table does not mean that people have truth tables in mind at all. We share with the Stoic logicians the notion that the material conditional is a paradoxical way to understand the meaning of conditionals, and a conditional is not true whenever its antecedent is false, and we share with the Stoics the notion that the meaning of a logic particle is found in the inference forms that it sanctions. From this perspective, the meaning of if is found in its suppositional role, and one needs to know which inferences are sanctioned by propositions expressed with it.

To illustrate further the point that the meaning of a logic particle or a logic quantifier is found in the inferences it sanctions, consider the quantifiers all and some. Note that the universe of discourse for a proposition containing such a quantifier is infinite, e.g., all numbers ending in zero cannot be represented in a finite truth table. Nonetheless, the meaning of expressions containing such words can be quite clear. Suppose that you know that all of the boys in the third grade went to the museum and that Juan is one of the third grade boys; you could assert that Juan went to the museum. If you knew instead that some of the boys in the third grade went to the museum and that Juan is one of the third grade boys, you could not assert that Juan went to the museum. Someone who did not understand that the inference about Juan going to the museum can be made in one instance, but not the other, could not be said to understand the meanings of the two quantifiers all and some. Knowing what inferences a logic particle or quantifier supports provides a logical semantics for that particle or quantifier and this does not refer to any truth table.

The idea of basing psychological reasoning research on commonalities among truth tables that could be assigned to various propositional surface-structures is likely to lead down many odd paths, and, indeed, it can spin into a burgeoning set of surface-structure expressions. For example, the truth table for not both $p$ and $q$-the sort of proposition that provides the major premise for the modus tollendo ponens argument of Chrysippus and

\footnotetext{
${ }^{5}$ This sort of negation-introduction schema can be found in natural logic systems of the sort introduced by Gentzen, 1934.
} 
for one of the schemas included in the mental logic of Braine and O'Brien- would seem to lead to the following truth- table assignments:

\begin{tabular}{ccc}
$\mathrm{p}$ & $\mathrm{q}$ & not both p and $\mathrm{q}$ \\
\hline $\mathrm{t}$ & $\mathrm{t}$ & $\mathrm{f}$ \\
$\mathrm{f}$ & $\mathrm{t}$ & $\mathrm{t}$ \\
$\mathrm{t}$ & $\mathrm{f}$ & $\mathrm{t}$ \\
$\mathrm{f}$ & $\mathrm{f}$ & $\mathrm{t}$
\end{tabular}

so the expression that seems to parallel both if $p$ then $q$ and not-p or $q$ becomes:

\begin{tabular}{ccc}
$\mathrm{p}$ & $\mathrm{q}$ & not both $\mathrm{p}$ and not-q \\
\hline $\mathrm{t}$ & $\mathrm{t}$ & $\mathrm{t}$ \\
$\mathrm{f}$ & $\mathrm{t}$ & $\mathrm{t}$ \\
$\mathrm{t}$ & $\mathrm{f}$ & $\mathrm{f}$ \\
$\mathrm{f}$ & $\mathrm{f}$ & $\mathrm{t}$
\end{tabular}

Likewise, neither $p$ nor $q$, which also could be expressed in English as not $p$ and not $q$, could have the following truth-table assignments:

\begin{tabular}{ccc}
$\mathrm{p}$ & $\mathrm{q}$ & neither $\mathrm{p}$ nor $\mathrm{q}$ \\
\hline $\mathrm{t}$ & $\mathrm{t}$ & $\mathrm{f}$ \\
$\mathrm{f}$ & $\mathrm{t}$ & $\mathrm{f}$ \\
$\mathrm{t}$ & $\mathrm{f}$ & $\mathrm{f}$ \\
$\mathrm{f}$ & $\mathrm{f}$ & $\mathrm{t}$
\end{tabular}

so the equivalent expression to if $p$ then $q$ would become:

\begin{tabular}{ccc}
$\mathrm{p}$ & $\mathrm{q}$ & neither not-p nor $\mathrm{q}$ \\
\hline $\mathrm{t}$ & $\mathrm{t}$ & $\mathrm{t}$ \\
$\mathrm{f}$ & $\mathrm{t}$ & $\mathrm{t}$ \\
$\mathrm{t}$ & $\mathrm{f}$ & $\mathrm{f}$ \\
$\mathrm{f}$ & $\mathrm{f}$ & $\mathrm{f}$
\end{tabular}

Let me suggest that a research program that addresses the equivalences in meaning, or lack thereof, among if $p$ then $q$, not $p$ or $q$, not both $p$ and not- $q$, neither not- $p$ nor $q$, and not both not- $p$ and $q$ that is invited when one proposes that the meaning of a logic operator is provided by its truth table would inhabit a strange cognitive world. The comparison of if not-p then $q$ to $p$ or $q$ that was undertaken by Liu and Chou merely scratches the surface of expressions that can be mapped onto the truth table for the material conditional, and 
a complete set of comparisons of all of these expressions with the same set of content, together with the reduced and complete versions of the syllogisms tasks used by Liu and Chou would be something of an Alice-down-the- rabbit-hole venture.

Liu and Chou (2012) were correct to reject the notion that a table of truth functional assignments, such as the material conditional, reasonably might account for the meaning of particles like if and or. However rejecting the material conditional as an account of the meaning of words like if and or does not by itself provide a theory of the meanings of these words, and Liu and Chou did not provide such a theory. All that their two-step theory of reasoning about two-premise syllogisms has accomplished is concluding that if and or have different meanings from one another; by itself it addresses nothing about what those meanings are and what makes them different from one another. Nonetheless, I thank them for having pointed out that truth tables alone are not adequate for providing a psychological account of how people reason to and from propositions containing such words, and I suggest that they consider the inference schemas and the reasoning program of mental-logic theory as a way of filling in the lacunae in their exegesis concerning what if and or contribute to such problems.

Understanding exactly how the two-step theory proposed by Liu and Chou works remains difficult. Their title-successive conditionalization-and the names of the two steps -first and second conditionalizations- suggests that the two steps happen in a sequence, although they also say that they may be processed concurrently. Further, if they do happen sequentially, then the words if or or seem almost an afterthought, not coming into any computations until late in the process, that is, only in the second and final step. One presumes that their approach is supposed to account not only for the particular way of presenting information that was used in their experiments, but is of interest because it has the potential to account for the sorts of content effects often reported with conditionalsyllogism tasks; but typically the first premise encountered in a conditional syllogism is the major premise, that is, the proposition containing if, and it would be quite odd if the information that enters the system first is the last piece of information processed.

An additional limitation of their two-step theory is that it is quite narrow in its applicability; the computation of the first conditionalization applies only to a minor premise and a tentative conclusion to be evaluated, but many laboratory tasks, as well as almost all reasoning situations outside of the laboratory, do not have a single minor premise and a conclusion to be evaluated. To illustrate the point, consider the following two reasoning problems from O’Brien, Braine, and Yang (1994), both of which presented a set of premises with no conclusion, and instructions to write down everything that can be inferred from the premises in the order in which the inferences are made:

Premise Set 1
(a) $\mathrm{N}$ or $\mathrm{P}$
(b) Not N
(c) If $\mathrm{P}$ then $\mathrm{H}$
(d) If $\mathrm{H}$ then $\mathrm{Z}$
(e) Not both $Z$ and $S$
(a) Not both $A$ and $S$
(b) If $\mathrm{H}$ then $\mathrm{Z}$
(c) If $P$ then $Z$
(d) Not N
(e) $\mathrm{N}$ or $\mathrm{P}$

Premise Set 2 
Because the problems did not contain a major and a minor premise, nor did they present a tentative conclusion to be evaluated, there is no clear way in which the computations either of the first conditionalization or of the second conditionalization of Liu's and Chou's theory could be computed. Yet the two premise sets lead consistently to a predictable set of inferences being written down by research participants.

How do participants process the information in these problems? Let's turn to Premise Set 1 first. Almost all the college students who participated in this study wrote down first $\mathrm{P}$, then $\mathrm{H}$, then $\mathrm{A}$, and finally not $\mathrm{S}$, which is the sequence of inferences that would occur if a participant were applying the schemas and the DRR of Braine's and O'Brien's mental-logic theory. Now let's turn to Premise Set 2, where almost all the college students made exactly the same sequence of inferences even though the premises were presented in reverse order; mental-logic theory predicts the same sequence of inferences on both problem sets because the order of inferences is predicted from the availability of the inference schemas, and no schemas are available on reading the premises of Set 2 can be applied until $N$ or $P$ and $N o t N$ are held together in working memory, which comes at the end of reading all the premises. Note also that neither of these problems presented a tentative conclusion to be evaluated, and neither had a major or a minor premise. The theory of Liu and Chou fails to instruct the problem solver to compute anything for these two problems, but mental-logic theory is not limited to syllogistic forms with a major and a minor premise, and can be applied to sets of multiple premises; it also does not require that a tentative conclusion be available for consideration to tell the reasoner when to begin processing the information, and it accounts for the fact that the same set of inferences are made in the same order on the two problems, none of which the procedures of Liu and Chou can do. Unlike Liu's and Chou's procedures, which do not capture anything of the meanings of the logic particles, the mental-logic theory provides a robust set of schemas which together define what inferences can be made-thus providing a procedural semantics for the particles. The Liu and Chou proposal addresses an interesting question: how certain sorts of content influence the extent to which premises are accepted, and as such it could be a useful supplement to mental- logic theory that by itself does not address this issue (although the issue is included under the set of pragmatic principles), but unless the processes described by Liu and Chou are combined with something that provides an account of the meanings of logic particles like if and or, their account leaves out the logic in logical reasoning and provides no explanation of how if and or contribute to the systematic variance in the data they report.

Although the two-step theory of Liu and Chao is difficult to understand and is of limited applicability when understood as a reasoning theory, the two steps are quite clear as a method of separating the contributions of a logical operator from the content of the propositions. Nonetheless, a clever research method should not be confused with a reasoning theory. If they want us to accept the two-step approach as more than methodological, they will have to spell out clearly how its steps are applied as the premises of a wider set of reasoning problem are encountered, that is, the theory would have to apply to more than a narrow set of problems with major and minor premises and a tentative conclusion to be evaluated. 


\section{REFERENCES}

Barnes, Jonathan, Bobzien, Susanne \& Mignucci, Mario."Logic". In Keimpe Algra et al. The Cambridge History of Hellenistic Philosophy. Cambridge, UK: Cambridge University Press, (1999): 92-176.

Beth, Evert W \& Piaget, Jean. Mathematical Epistemology and Psychology. Dordrecht, The Netherlands: D. Reidel, 1966.

Bobzien, Susanne. "The Development of Modus Ponens in Antiquity: From Aristotle to the 2nd Century", Phronesis 47/4 (2002): 359-394.

Braine, Martin D. S., \& O’Brien, David P. “A theory of if: A lexical entry, reasoning program, and pragmatic principles", Psychological Review 98 (1991): 182-203. Reprinted in Martin D. S. Braine \& David P. O’Brien (Eds.), Mental logic. pp. 199-244. Mahwah, NJ: Lawrence Erlbaum Associates. Braine, Martin D. S. \& O’Brien, David P. Mental logic. Hillsdale, NJ: Lawerence Erlbaum Associates, 1998.

Braine, Martin D. S., Reiser, Brian J., \& Rumain, Barbara. "Some empirical justifications for a theory of natural propositional logic". In Gordon H. Bower (Ed.), The psychology of learning and motivation. New York: Academic Press, (1984): 313371.

Gentzen, Gerhard. "Untersuchungen über das logische. I", Mathematische Zeitschrift 39 (1934): 176-210.

Henle, Mary. "On the relation between logic and thinking", Psychological Review 69 (1962): 366-378.

Kapp, Ernst. Greek Foundations of Traditional Logic. New York: Columbia University Press, 1942.

Kneale, William \& Kneale, Martha. The Development of Logic. Oxford: Clarendon Press, 1962.

Liu, In Mao \& Chou, Ting-his. "A successive-conditionalization approach to disjunctive and syllogistic reasoning", Psychological Research 76 (2012): 676-692.

López Astorga, Miguel. "Are conditional and disjunction really comparable?", Universum 28/2 (2013): 229-242.

O’Brien, David P. "Human reasoning requires a mental logic", Behavioral and Brain Sciences 32 (2009): 96-97. 
O’Brien, David P., Braine, Martin D. S., \& Yang, Yungri. "Propositional reasoning by model: Simple to refute in principle and in practice", Psychological Review 101 (1994): 711-724.

O’Brien, David P., Dias, Maria G., Roazzi, Antonio \& Braine, Martin D. S. "Conditional reasoning: The logic of supposition and children's understanding of pretense". In Martin D. S. Braine \& David P. O’Brien (Eds.), Mental logic. Mahwah, NJ: Lawrence Erlbaum Associates, (1998): 245-272.

O’Brien, David P. \& Li, Shujing. "Mental Logic Theory: A Paradigmatic Case for Empirical Research on the Language of Thought and Inferential Role Semantics", Journal of Foreign Languages 36/6 (2013): 27-41.

Rips, Lance J. The psychology of proof: Deduction in human thinking. Cambridge, MA: MIT Press, 1994. 